\title{
The Effects of Nurses' Knowledge of Withdrawal of Life- Sustaining Treatment, Death Anxiety, Perceptions of Hospice on Their Attitudes toward Withdrawal of Life-Sustaining Treatment
}

\author{
Young Eun Lee, R.N., Ph.D., Yu Jin Jung, R.N., M.S., \\ Yoo Na Jang, R.N., Ph.D.* and Hyo Eun Jeong, R.N., Ph.D. ${ }^{\dagger}$ \\ College of Nursing, Kosin University, Busan, "Department of Nursing, Kyongbuk Science College, Chilgok, \\ ${ }^{\dagger}$ Kosin University Research Institute of Wholistic Nursing Science, Busan, Korea
}

Purpose: This descriptive study investigated the effects of nurses' knowledge of withdrawal of life-sustaining treatment, death anxiety, and perceptions of hospice care on their attitudes toward withdrawal of life-sustaining treatment. Methods: Data were collected from 262 nurses at tertiary hospitals, general hospitals, or primary hospitals in Busan, Korea, and statistically analyzed using the t-test, analysis of variance, the Scheffé test, Pearson correlation coefficients, and hierarchical regression analysis. Results: The participants' scores were $3.68 \pm 0.45$ (out of 5) for attitudes toward withdrawal of life-sustaining treatment, $0.65 \pm$ 0.15 (out of 1) for knowledge of withdrawal of life-sustaining treatment, $2.61 \pm 0.26$ (out of 4) for death anxiety, and $4.06 \pm 0.43$ (out of 5) for perceptions of hospice care. Furthermore, knowledge of withdrawal of life-sustaining treatment and perceptions of hospice care showed positive correlations with attitudes toward withdrawal of life-sustaining treatment, while death anxiety showed a negative correlation. The most significant factors influencing attitudes toward withdrawal of life-sustaining treatment were perceptions of hospice care, followed by having experienced caring for patients who withdrew life-sustaining treatment, death anxiety, having a spouse, and ethical values, and the overall explanatory power was 43.0\%. Conclusion: This study showed that perceptions of hospice were an important factor influencing nurses' attitudes toward withdrawal of life-sustaining treatment. Therefore, it is necessary to develop and validate educational intervention programs that can improve perceptions of hospice care.

Key Words: Nurses, Hospice care, Anxiety, Attitude, Terminal care
Received February 22, 2020

Revised July 28, 2020

Accepted July 30, 2020

\section{Correspondence to}

Yu Jin Jung

ORCID:

https://orcid.org/0000-0002-3079-7597

E-mail: jung.yj.85@gmail.com

This research was supported by

funding from Kosin University.

\section{INTRODUCTION}

\section{Background}

According to a report of the National Agency for Management of Life-Sustaining Treatment, the number of people who planned withdrawal of life-sustaining treatment (WLST) increased from 1,125 to 31,616 between March 2018 and October 2019, and the number of people who withdrew lifesustaining treatment increased sharply from 1,380 to 70,966 [1]. Discussions about whether futile life-prolonging treatment infringes on an individual's right to self-determination led to the enactment of the Act on Hospice and Palliative Care and Decisions on Life-Sustaining Treatment for Patients at the End 
of Life (hereinafter referred to as the Act on Decisions on LifeSustaining Treatment). The Act was designed to protect the right to forgo or discontinue life-sustaining treatment, which extends only to the prolongation of the end-of-life process without a curative effect in patients facing impending death, and it has been amended. In March 2019, the scope of the Act was expanded to include the following as life-sustaining treatments: use of extracorporeal life support, blood transfusion, administration of vasopressors, and other medical procedures that are not performed by the physician in charge of the patient's care or considered necessary to be terminated [2]. The Ministry of Health and Welfare pledged to undertake additional projects to promote implementation of the Act in medical institutions across the country and to improve the quality of the participating institutions by 2023 [3]. Thus, in line with changing perceptions of end-of-life decisions and the relevant legal framework, nurses need to recognize the new medical situation and prepare to respond appropriately.

Attitudes toward WLST refer to an individual's positive or negative feelings toward a decision to discontinue lifeprolonging interventions [4]. Nurses should assess patients' and caregivers' requests for WLST, provide correct information in response to their requests, collaborate with the rest of the medical team to provide emotional support for the patients and caregivers, and help the bereaved families to move on with their lives [5]. However, nurses have been found to suffer from negative emotions such as ethical conflicts, guilt, and depression while processing and implementing WLST [6]. This negative sentiment was reported to impair nurses' ability to respect patients' right to self-determination and recognize their role in WLST, resulting in improper provision of medical care for patients on their deathbeds $[7,8]$. Therefore, it is imperative for nurses to have positive attitudes toward WLST before practicing WLST-related nursing care.

According to Ostrom [9], cognitive, affective, and behavioral components make up an individual's attitudes, and the cognitive component includes a person's beliefs and subjective knowledge. In other words, the level of knowledge acquired by an individual helps to determine whether he or she has a positive or negative attitude towards something. In previous studies that confirmed the relationship between knowledge of and attitudes toward WLST, higher levels of knowledge were associ- ated with more positive attitudes among nursing students [10], whereas nurses had more negative attitudes [11]. Likewise, studies have shown contradictory results on the relationship between knowledge of and attitudes toward WLST depending on the study participants. Therefore, we believe it is necessary to re-examine the relationship between nurses' knowledge of WLST and their attitudes toward WLST at this time when the Act on Decisions on Life-Sustaining Treatment is enforced.

Another component of an individual's attitudes, as described by Ostrom [9], is affective. Considering that death anxiety refers to emotional responses elicited by death-related thoughts or expectations, such as discomfort, apprehension, unease, and fear [12], we conjectured that these emotions could affect the formulation of an individual's attitude towards WLST. Indeed, some previous studies reported that death anxiety was associated with attitudes toward WLST [13,14]. Among elderly patients with cancer, higher levels of death anxiety were associated with more negative attitudes toward WLST [13], whereas among the general population and nurses, higher death anxiety was associated with more positive attitudes toward WLST [14]. Although these studies showed that death anxiety was associated with attitudes toward WLST, they presented conflicting results depending on the study participants, and we believe that this discrepancy warrants further research.

The perception of hospice care refers to distinguishing and recognizing the concept of medical care provided to patients on their deathbeds and their families for the purpose of evaluating and treating physical (pain and symptoms), social, and spiritual aspects of health $[2,15]$. Since the domain of personal perception refers to cognizant thinking and knowing, the perceptual domain is also a cognitive component that formulates an individual's attitudes [9], and an individual's perceptions of hospice care (i.e., perceptions of medical care dealing with death) could be related to an individual's attitudes toward WLST (i.e., attitudes toward death). In previous studies, higher perceptions of hospice care were associated with more positive attitudes toward WLST among nursing students, medical personnel, and administrative staff working at tertiary hospitals $[4,16]$. However, such a relationship has yet to be confirmed in studies involving only clinical nurses. Moreover, the characteristics of hospice care for patients on their deathbed are closely linked to death, and knowledge accumulated from the 
experience of implementing WLST changes nurses' point of view on death [6], while knowledge from formal education affects individuals' perceptions of hospice care and attitudes toward death [17]. Therefore, we think that it is necessary to conduct a comprehensive study to elucidate the influence of clinical nurses' knowledge of WLST, death anxiety, and perceptions of hospice care on their practice of end-of-life care for terminally ill patients in association with their attitudes toward WLST.

The purpose of this study was to determine the influence of clinical nurses' knowledge of WLST, death anxiety, and perceptions of hospice care on their attitudes toward WLST and to provide basic data for educational programs designed to foster positive changes in their attitudes toward WLST, focusing on the identified factors.

\section{Purpose}

The purpose of this study was to identify the effects of knowledge of WLST, death anxiety, and perceptions of hospice care among clinical nurses on their attitudes toward WLST. The specific objectives of the study were as follows:

1) To identify the extent of differences in participants' attitudes toward WLST according to their general characteristics.

2) To identify participants' level of knowledge of WLST, death anxiety, perceptions of hospice care, and attitudes toward WLST.

3) To identify the relationships of participants' knowledge of WLST, death anxiety, and perceptions of hospice care with their attitudes toward WLST.

4) To identify the factors affecting participants' attitudes toward WLST.

\section{METHODS}

\section{Study design}

This descriptive survey study was conducted to identify the effects of knowledge of WLST, death anxiety, and perceptions of hospice care on clinical nurses' attitudes toward WLST.

\section{Study participants and data collection}

The participants in this study were clinical nurses working at
K University Hospital, S General Hospital, K Hospital, and I Nursing Hospital, all of which are located in B metropolitan city. The participants were selected via convenience sampling as those who voluntarily agreed to participate in the study after being informed of the purpose and methods of the study.

The number of participants needed for the study was calculated using $G^{*}$ Power version 3.0.10. In multiple regression analysis, the number of participants required was estimated to be 230 , assuming a significance level of 0.05 , a medium effect size of 0.15 , a power of 0.95 , and 22 predictors. However, considering a dropout rate of $20 \%$, data were collected from 276 participants. With the exclusion of 14 incomplete questionnaires, 262 complete surveys were included in the final analysis.

Data collection was performed after receiving institutional review board approval from K University (KU IRB 20190014) from June 4 to August 30, 2019, after obtaining permission from the head of the corresponding department of each institution. The authors explained the purpose of the study and obtained signatures from those who agreed to participate in the study before distributing the self-report questionnaires. The study participants took approximately 15 minutes to complete the questionnaire.

\section{Research tool}

In this study, we used a structured questionnaire that consisted of a total of 101 questions, including 19 questions on knowledge of WLST, 35 questions on death anxiety, 15 questions on perceptions of hospice care, 14 questions on attitudes toward WLST, and 18 questions on general characteristics.

\section{1) Knowledge of WLST}

To assess participants' knowledge of WLST, we revised and supplemented the assessment tool devised by Jung [4] to reflect the Act on Decisions on Life-Sustaining Treatment revised in March 2019, as the tool is a revised and supplemented version of the assessment tool developed by Kim [18] based on the previous version of the Act on Decisions on Life-Sustaining Treatment, which was enacted in 2017. Moreover, we consulted two hospice palliative care specialists to enhance the content validity.

There were 19 questions in total in this domain. The pos- 
sible responses were "yes," "no," and "don't know" for each question; 'don't know' was considered as an error, and higher scores were considered to indicate higher levels of knowledge of WLST. In the study by Jung [4], the Cronbach's $\alpha$ was 0.60 , whereas in the current study, the value was 0.71 .

\section{2) Death anxiety}

To assess death anxiety, we used the Fear of Death and Dying Scale, which was developed by Collette and Lester [19] and translated into Korean by Suh [20].

The total number of questions in this domain was 35. Each question was scored on a 4-point Likert scale with 1 being "rarely fearful" and 4 being "very fearful." A higher score indicated a higher level of death anxiety. In the study by Suh [20], Cronbach's $\alpha$ was 0.91 , whereas in the current study, the value was 0.79 .

\section{3) Perceptions of hospice care}

Perceptions of hospice care were assessed using the tool devised by Han and Lee [21]. There were 15 questions in this domain, and each question was scored using a 5-point Likert scale, with 1 being "not aware at all" and 5 being "fully aware." A higher score indicated a higher perception of hospice care. In the study by Han and Lee [21], the Cronbach's $\alpha$ value for each subdomain was as follows: purpose of hospice care, 0.83; necessity of hospice care, 0.64. In the current study, the value for the overall perception of hospice care was 0.84 , with the value for the purpose of hospice care being 0.91 and that for its necessity being 0.74 .

\section{4) Attitudes toward WLST}

To assess participants' attitudes toward WLST, we revised and supplemented the assessment tool developed by Jung [4] to reflect the Act on Decisions on Life-Sustaining Treatment revised in March 2019, as the tool is a revised and supplemented version of the assessment tool developed by Byun et al. [22] based on the previous Act on Decisions on LifeSustaining Treatment, which was enacted in 2017. Moreover, we consulted two hospice palliative care specialists to enhance the content validity.

The total number of questions in this domain was 14. Each response was scored using a 5 -point Likert scale with 1 be- ing "not positive at all" and 5 being "very positive." A higher score indicated a more positive attitude. In the study by Jung [4], Cronbach's $\alpha$ was 0.60 , whereas in the current study, the value was 0.79 .

\section{Data analysis}

The data collected in this study were analyzed using SPSS for Windows version 18.0 (SPSS Inc., Chicago, IL, USA) as follows:

1) The general characteristics of the participants were analyzed by number, percentage, and mean and standard deviation.

2) Differences in attitudes toward WLST according to general characteristics were analyzed using the $t$-test, analysis of variance, and the Scheffé test.

3) The participants' knowledge of WLST, death anxiety, perceptions of hospice care, and attitudes toward WLST were analyzed in terms of the minimum, maximum, and mean and standard deviation.

4) The correlations between the participants' knowledge of WLST, death anxiety, and perceptions of hospice care with their attitudes toward WLST were analyzed by Pearson correlation coefficients.

5) The factors influencing participants' attitudes toward WLST were analyzed by hierarchical regression analysis.

\section{RESULTS}

\section{General characteristics of study participants}

The mean age of the clinical nurses who participated in this study was $32.50 \pm 8.13$ years, and the largest number of participants $(n=125,47.4 \%)$ were aged 22 to 29 years. Most participants had graduated from a 3- or 4-year college $(n=223,85.1 \%)$, were religious $(n=161,61.5 \%)$, had no spouse ( $n=177,67.65 \%)$, and had no children ( $n=196,74.8 \%)$. Most participants $(n=170,64.9 \%)$ worked at a tertiary hospital or general hospital. The majority of participants had experience providing nursing care for patients with terminal illness or on their deathbed $(n=177,67.8 \%)$ or those who withdrew lifesustaining treatment $(n=167,63.7 \%)$, had strong ethical values $(n=169,64.5 \%)$, and had not received education on hospice 
Table 1. Differences in Attitudes toward Withdrawal of Life-Sustaining Treatment (WLST) by General and Occupational Characteristics ( $N=262)$.

\begin{tabular}{|c|c|c|c|c|c|}
\hline \multirow{2}{*}{\multicolumn{2}{|c|}{ Variables }} & \multirow{2}{*}{$\begin{array}{l}\mathrm{N}(\%) \text { or } \\
\text { Mean } \pm \text { SD }\end{array}$} & \multicolumn{3}{|c|}{ Attitudes toward WLST } \\
\hline & & & Mean $\pm S D$ & tor $F$ & $P(*)$ \\
\hline Age (yr) & $\begin{array}{l}22 \sim 29^{a} \\
30 \sim 39^{b} \\
\geq 40^{c}\end{array}$ & $\begin{array}{r}125(47.7) \\
82(31.3) \\
55(21.0) \\
32.50 \pm 8.13\end{array}$ & $\begin{array}{l}50.38 \pm 5.68 \\
51.59 \pm 7.27 \\
53.91 \pm 5.62\end{array}$ & 6.20 & $\begin{array}{l}0.002 \\
(b<c)\end{array}$ \\
\hline Education & $\begin{array}{l}\text { College or university } \\
\geq \text { Master's }\end{array}$ & $\begin{array}{r}223(85.1) \\
39(14.9)\end{array}$ & $\begin{array}{l}51.03 \pm 6.14 \\
54.18 \pm 6.80\end{array}$ & -2.91 & 0.004 \\
\hline Religion & $\begin{array}{l}\text { Yes } \\
\text { No }\end{array}$ & $\begin{array}{l}161(61.5) \\
101(38.5)\end{array}$ & $\begin{array}{l}52.24 \pm 6.52 \\
50.32 \pm 5.87\end{array}$ & -2.41 & 0.017 \\
\hline Participant in religion ${ }^{\dagger}(n=156)$ & $\begin{array}{l}\text { Active participation } \\
\text { Participation } \\
\text { Not participation }\end{array}$ & $\begin{array}{l}50(32.0) \\
58(37.2) \\
48(30.8)\end{array}$ & $\begin{array}{l}52.20 \pm 5.82 \\
53.50 \pm 6.39 \\
50.52 \pm 7.12\end{array}$ & 1.17 & 0.272 \\
\hline Perceived health status & $\begin{array}{l}\text { Good } \\
\text { Bad }\end{array}$ & $\begin{array}{r}232(88.5) \\
30(11.5)\end{array}$ & $\begin{array}{l}51.49 \pm 6.42 \\
51.53 \pm 5.69\end{array}$ & -0.03 & 0.973 \\
\hline Spouse & $\begin{array}{l}\text { Yes } \\
\text { No }\end{array}$ & $\begin{array}{r}85(32.4) \\
177(67.6)\end{array}$ & $\begin{array}{l}54.00 \pm 6.37 \\
50.29 \pm 5.97\end{array}$ & -4.60 & $<0.001$ \\
\hline Child status & $\begin{array}{l}\text { Yes } \\
\text { No }\end{array}$ & $\begin{array}{r}66(25.2) \\
196(74.8)\end{array}$ & $\begin{array}{l}53.71 \pm 6.46 \\
50.75 \pm 6.13\end{array}$ & -3.35 & 0.001 \\
\hline $\begin{array}{l}\text { Monthly income }(10,000 \text { won })^{\dagger} \\
\quad(n=214)\end{array}$ & $\begin{array}{l}<500 \\
\geq 500\end{array}$ & $\begin{array}{c}115(53.7) \\
99(46.3) \\
494.95 \pm 261.05\end{array}$ & $\begin{array}{l}50.43 \pm 5.98 \\
52.99 \pm 6.51\end{array}$ & -3.00 & 0.003 \\
\hline Total clinical career (mo) & $\begin{array}{l}<72 \\
\geq 72\end{array}$ & $\begin{array}{c}132(50.4) \\
130(49.6) \\
109.84 \pm 97.36\end{array}$ & $\begin{array}{l}50.42 \pm 5.72 \\
52.60 \pm 6.75\end{array}$ & -2.81 & 0.005 \\
\hline Working hospital & $\begin{array}{l}\text { General or tertiary hospital } \\
\text { Primary Hospital }\end{array}$ & $\begin{array}{r}170(64.9) \\
92(35.1)\end{array}$ & $\begin{array}{l}52.52 \pm 6.38 \\
49.60 \pm 5.82\end{array}$ & 3.65 & $<0.001$ \\
\hline Working unit ${ }^{\dagger}(n=247)$ & 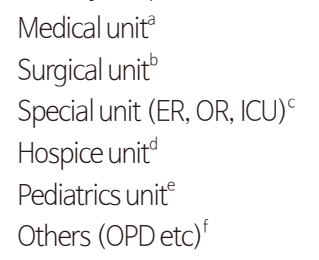 & $\begin{array}{l}89(36.0) \\
54(21.9) \\
41(16.6) \\
27(10.9) \\
25(10.1) \\
11(4.5)\end{array}$ & $\begin{array}{l}52.49 \pm 5.46 \\
50.07 \pm 6.90 \\
48.34 \pm 5.83 \\
57.00 \pm 5.76 \\
51.88 \pm 6.08 \\
50.82 \pm 6.57\end{array}$ & 7.93 & $\begin{array}{c}<0.001 \\
(\mathrm{~d}>\mathrm{a}, \mathrm{b}, \mathrm{c}, \mathrm{a}>\mathrm{c})\end{array}$ \\
\hline $\begin{array}{l}\text { Experience of caring for terminal } \\
\text { or end of life patients }{ }^{\dagger}(n=261)\end{array}$ & $\begin{array}{l}\text { Yes } \\
\text { No }\end{array}$ & $\begin{array}{r}177(67.8) \\
84(32.2)\end{array}$ & $\begin{array}{l}52.81 \pm 6.17 \\
48.85 \pm 5.78\end{array}$ & -4.94 & $<0.001$ \\
\hline $\begin{array}{l}\text { Experience of caring for WLST } \\
\text { patients }\end{array}$ & $\begin{array}{l}\text { Yes } \\
\text { No }\end{array}$ & $\begin{array}{r}167(63.7) \\
95(36.3)\end{array}$ & $\begin{array}{l}53.06 \pm 5.81 \\
48.75 \pm 6.30\end{array}$ & -5.60 & $<0.001$ \\
\hline $\begin{array}{l}\text { Experience of death of family } \\
\text { members or relatives }\end{array}$ & $\begin{array}{l}\text { Yes } \\
\text { No }\end{array}$ & $\begin{array}{r}219(83.6) \\
43(16.4)\end{array}$ & $\begin{array}{l}51.42 \pm 6.15 \\
51.88 \pm 7.24\end{array}$ & 0.44 & 0.662 \\
\hline Ethical values & $\begin{array}{l}\text { Defined } \\
\text { Undefined }\end{array}$ & $\begin{array}{r}169(64.5) \\
93(35.5)\end{array}$ & $\begin{array}{l}52.57 \pm 6.65 \\
49.54 \pm 5.18\end{array}$ & 3.81 & $<0.001$ \\
\hline Hospice education & $\begin{array}{l}\text { Yes } \\
\text { No }\end{array}$ & $\begin{array}{l}118(45.0) \\
144(55.0)\end{array}$ & $\begin{array}{l}52.39 \pm 6.37 \\
50.76 \pm 6.23\end{array}$ & -2.08 & 0.038 \\
\hline WLST education & $\begin{array}{l}\text { Yes } \\
\text { No }\end{array}$ & $\begin{array}{r}87(33.2) \\
175(66.8)\end{array}$ & $\begin{array}{l}53.00 \pm 6.50 \\
50.75 \pm 6.13\end{array}$ & -2.74 & 0.006 \\
\hline Perceived empathy ability & $\begin{array}{l}\text { Good } \\
\text { Bad }\end{array}$ & $\begin{array}{r}207(79) \\
55(21)\end{array}$ & $\begin{array}{l}51.59 \pm 6.41 \\
51.13 \pm 6.07\end{array}$ & 0.49 & 0.628 \\
\hline
\end{tabular}

*Scheffétest, ${ }^{\dagger}$ Excluded non-responses to the question.

ER: emergency room, OR: operating room, ICU: intensive care unit, OPD: outpatient department. 
care $(n=144,55.0 \%)$ or WLST $(n=175,66.8 \%)$ (Table 1$)$.

\section{Participants' knowledge of WLST, death anxiety, perceptions of hospice care, and attitudes toward WLST}

The mean score for knowledge of WLST was $0.65 \pm 0.15$ points out of 1 point. Death anxiety averaged $2.61 \pm 0.26$ points out of 4 points. The average score for perceptions of hospice care was $4.06 \pm 0.43$ points out of 5 points. The average scores for the subdomains of the perceptions of hospice care were as follows: $4.28 \pm 0.55$ points for the purpose of hospice care and $3.91 \pm 0.47$ for the necessity of hospice care. The average score for attitudes toward WLST was $3.68 \pm 0.45$ points out of 5 points (Table 2).

\section{Attitudes toward WLST according to participants' general characteristics}

The following general characteristics of the participants had a statistically significant influence on their attitudes toward WLST: age ( $\mathrm{F}=6.20, \mathrm{P}=0.002)$, education $(\mathrm{t}=-2.91, \mathrm{P}=0.004)$, religion ( $\mathrm{t}=-2.41, \mathrm{P}=0.017)$, marital status $(\mathrm{t}=-4.60, \mathrm{P}<0.001)$, having a child $(\mathrm{t}=-3.35, \mathrm{P}=0.001)$, monthly household income $(t=-3.00, P=0.003)$, length of experience in clinical nursing $(\mathrm{t}=-2.81, \mathrm{P}=0.005)$, type of hospital $(\mathrm{t}=3.65, \mathrm{P}<0.001)$, hospital department $(\mathrm{F}=7.93, \mathrm{P}<0.001)$, having experienced providing nursing care for terminally ill or end-of-life patients $(\mathrm{t}=-4.94, \mathrm{P}<0.001)$, having experienced providing nursing care for patients who withdrew life-sustaining treatment $(\mathrm{t}=-$ 5.60, $\mathrm{P}<0.001)$, ethical values ( $\mathrm{t}=3.81, \mathrm{P}<0.001)$, hospice care education $(\mathrm{t}=-2.08, \mathrm{P}=0.038)$, and education on WLST discontinuation $(t=-2.74$ and $\mathrm{P}=0.006)$ (Table 2$)$.

Table 2. Level of Knowledge of WLST, Death Anxiety, Perceptions of Hospice Care, and Attitudes toward WLST ( $\mathrm{N}=262)$.

\begin{tabular}{cc}
\hline \multicolumn{1}{c}{ Variables } & Mean \pm SD (Range) \\
\hline Knowledge of WLST & $0.65 \pm 0.15(0.05 \sim 1.00)$ \\
Death anxiety & $2.61 \pm 0.26(1.83 \sim 3.34)$ \\
Perceptions of hospice care & $4.06 \pm 0.43(2.73 \sim 5.00)$ \\
Purpose of hospice care & $4.28 \pm 0.55(2.83 \sim 5.00)$ \\
Need for hospice care & $3.91 \pm 0.47(2.22 \sim 5.00)$ \\
Attitudes toward WLST & $3.68 \pm 0.45(2.57 \sim 5.00)$ \\
\hline
\end{tabular}

WLST: Withdrawal of Life-Sustaining Treatment.

\section{Relationships of participants' knowledge of WLST, death anxiety, and perceptions of hospice care with their attitudes toward WLST}

The participants' attitudes toward WLST were positively correlated, at a statistically significant level, with their knowledge of WLST $(r=0.17, \mathrm{P}=0.005)$ and perceptions of hospice care $(r=0.50, P<0.001)$ and were negatively correlated with death anxiety $(\mathrm{r}=-0.31, \mathrm{P}<0.001)$. These results indicate that higher levels of knowledge of WLST and perceptions of hospice care and lower levels of death anxiety were associated with more positive attitudes toward WLST (Table 3).

\section{Factors affecting the participants' attitudes to- ward WLST}

To determine the factors affecting attitudes toward WLST, we conducted hierarchical regression analysis with the following independent variables, which were identified as possible influencing factors based on our study results and a literature review: marital status, experience of providing nursing care for patients who withdrew life-sustaining treatment, ethical values, knowledge of WLST, death anxiety, and perceptions of hospice care. Marital status, experience of providing nursing care for patients who withdrew life-sustaining treatment, and ethical values (general characteristics) were treated as dummy variables in the analysis.

According to the analysis, the tolerance was higher than 0.1 for all variables (range, 0.898 to 0.986 ) and the variance inflation factor was lower than 10 for all variables (range, 1.014 to 1.114), indicating that there was no multicollinearity among the independent variables. Furthermore, in a residual analysis, the Durbin-Watson statistic was 2.019, which was close to 2,

Table 3. Correlations among Knowledge of WLST, Death Anxiety, Perceptions of Hospice Care, and Attitudes toward WLST ( $N=262)$.

\begin{tabular}{lccc}
\hline \multicolumn{1}{c}{ Variables } & $\begin{array}{c}\text { Knowledge } \\
\text { of WLST }\end{array}$ & Death anxiety & $\begin{array}{c}\text { Perceptions of } \\
\text { hospice care }\end{array}$ \\
\cline { 2 - 4 } & $r(P)$ & $r(P)$ & $r(P)$ \\
\hline Death anxiety & $-0.06(0.323)$ & & \\
Perceptions of hospice care & $0.11(0.077)$ & $-0.08(0.195)$ & \\
Attitudes toward WLST & $0.17(0.005)$ & $-0.31(<0.001)$ & $0.50(<0.001)$ \\
\hline
\end{tabular}

WLST: Withdrawal of Life-Sustaining Treatment. 
Table 4. Variables Influencing Attitudes toward the Withdrawal of Life-Sustaining Treatment (N=262).

\begin{tabular}{|c|c|c|c|c|c|c|c|c|c|c|c|c|}
\hline \multirow{2}{*}{ Variables } & \multicolumn{3}{|c|}{ Model I } & \multicolumn{3}{|c|}{ Model II } & \multicolumn{3}{|c|}{ Model III } & \multicolumn{3}{|c|}{ Model IV } \\
\hline & $B$ & S.E & $P$ & B & S.E & $P$ & B & S.E & $P$ & $B$ & S.E & $P$ \\
\hline (Constant) & 46.26 & 0.75 & $<0.001$ & 43.84 & 1.61 & $<0.001$ & 59.45 & 3.90 & $<0.001$ & 35.72 & 4.52 & $<0.001$ \\
\hline Spouse* & 3.63 & 0.75 & $<0.001$ & 3.67 & 0.75 & $<0.001$ & 3.42 & 0.72 & $<0.001$ & 2.34 & 0.66 & $<0.001$ \\
\hline $\begin{array}{l}\text { Experience of caring for } \\
\text { WLST patients* }\end{array}$ & 4.18 & 0.73 & $<0.001$ & 3.85 & 0.76 & $<0.001$ & 3.59 & 0.73 & $<0.001$ & 2.99 & 0.66 & $<0.001$ \\
\hline Ethical values* & 2.15 & 0.74 & 0.004 & 2.14 & 0.74 & 0.004 & 1.84 & 0.71 & 0.011 & 1.69 & 0.64 & 0.008 \\
\hline Knowledge of WLST & & & & 0.21 & 0.13 & 0.092 & 0.19 & 0.12 & 0.113 & 0.12 & 0.11 & 0.271 \\
\hline Death anxiety & & & & & & & -0.16 & 0.04 & $<0.001$ & -0.15 & 0.03 & $<0.001$ \\
\hline Perceptions of hospice care & & & & & & & & & & 0.40 & 0.05 & $<0.001$ \\
\hline $\mathrm{R}^{2}$ & \multicolumn{3}{|c|}{0.216} & \multicolumn{3}{|c|}{0.224} & \multicolumn{3}{|c|}{0.278} & \multicolumn{3}{|c|}{0.430} \\
\hline Adjusted R ${ }^{2}$ & \multicolumn{3}{|c|}{0.207} & \multicolumn{3}{|c|}{0.212} & \multicolumn{3}{|c|}{0.264} & \multicolumn{3}{|c|}{0.416} \\
\hline $\mathrm{F}$ & \multicolumn{3}{|c|}{23.671} & \multicolumn{3}{|c|}{18.598} & \multicolumn{3}{|c|}{19.737} & \multicolumn{3}{|c|}{31.998} \\
\hline P & \multicolumn{3}{|c|}{$<0.001$} & \multicolumn{3}{|c|}{$<0.001$} & \multicolumn{3}{|c|}{$<0.001$} & \multicolumn{3}{|c|}{$<0.001$} \\
\hline Durbin-Watson & & & & & & & & & & & 2.019 & \\
\hline VIF & \multicolumn{3}{|c|}{$1.014 \sim 1.027$} & \multicolumn{3}{|c|}{$1.015 \sim 1.093$} & \multicolumn{3}{|c|}{$1.021 \sim 1.100$} & \multicolumn{3}{|c|}{$1.032 \sim 1.114$} \\
\hline
\end{tabular}

WLST: Withdrawal of Life-Sustaining Treatment.

*Dummy variable: spouse ( $1=y e s, 0=$ no), experience of caring for WLST patients ( $1=y e s, 0=$ no), ethical values ( $1=$ defined, $0=$ undefined).

indicating that there was no autocorrelation among the sums of the errors of the models, thereby satisfying the assumptions of normality and equal variance of the residuals.

The results of model I in the regression analysis, which included the general characteristics of the participants as independent variables, showed that having a spouse $(B=3.63, P$ $<0.001$ ), experience of providing nursing care for patients who withdrew life-sustaining treatment, and strong ethical values were associated with positive attitudes toward WLST $(\mathrm{F}=23.671, \mathrm{P}<0.001)$, with an explanatory power of $21.6 \%$.

In model II in the regression analysis, which included knowledge of WLST as a major variable, the explanatory power increased by $0.8 \%$ to $22.4 \%$. In model III, which included death anxiety as a variable, the explanatory power increased by $5.4 \%$ compared to model II to $27.8 \%$. Finally, when perceptions of hospice care were additionally introduced into the analysis (model IV), the ability of the model to explain positive attitudes toward WLST increased to $43.0 \%$, up $15.2 \%$ from model III ( $\mathrm{F}=32.00, \mathrm{P}<0.001)$ (Table 4).

\section{DISCUSSION}

In this study, we sought to identify the level of knowledge of WLST, death anxiety, perceptions of hospice care, and atti- tudes toward WLST among clinical nurses, correlations among these variables, and factors influencing participants' attitudes toward WLST with the goal of providing a basis for facilitating positive attitudes toward WLST.

In the assessment of the clinical nurses' knowledge of WLST, the correct response rate was relatively low (65\%). This finding may be related to the fact that only $33.2 \%$ of the respondents reported that they had received education on WLST. Although the correct response rate in the current study was higher than 54\%, which was obtained from nursing students in the study by Jung [4] using the same assessment tool, the result still shows a lack of knowledge among nurses even after the Act on Decisions on Life-Sustaining Treatment came into force in 2017. This is a serious problem since nurses are supposed to deliver accurate information to their patients and caregivers who are considering or choosing whether to withdraw life-sustaining treatment. Therefore, it is imperative for the government to continue to promote perceptions of WLST among clinical nurses at the national level, as well as providing education on WLST.

The level of death anxiety among the clinical nurses in our study was moderate ( $2.61 \pm 0.26$ points out of 4 points). Similarly, Cho et al. [23], who used the same assessment tool, found a moderate level of death anxiety among nurses; how- 
ever, since the nurses' death anxiety was higher than that of physicians in their study, it may be necessary to reduce the level of death anxiety among nurses. Exposure to death causes death anxiety. In particular, clinical nurses experience emotional exhaustion when their work demands do not allow them to have time to express the grief that they feel in the face of patients' deaths and they have no choice but to suppress those feelings [6]. In view of this, clinical nurses should be given the opportunity to contemplate the meaning of life and death before being exposed to WLST situations. Furthermore, it is necessary to develop educational programs to reduce death anxiety among clinical nurses and counseling programs through which they can share their experiences of nursing dying patients, express condolences regarding their patients' deaths, and relieve their feelings.

The degree of clinical nurses' perceptions of hospice care was higher than moderate $(4.06 \pm 0.43$ points out of 5 point $)$ in our study, which is similar to the findings of Lee et al. [24], who reported higher than moderate scores for perceptions of the necessity of hospice care $(4.03 \pm 0.43$ points $)$ and the purpose of hospice care ( $4.55 \pm 0.47$ points), measured among nurses using the same assessment tool. In the study by Jung [4], who used the same assessment tool among nursing students, the level of perceptions of hospice care was also similar $(4.05 \pm 0.45$ points), which underscores the need for educational programs to further promote perceptions of hospice care among clinical nurses, considering that clinical nurses have more clinical field experience and nursing knowledge than nursing students and that the Act on Decisions on Life-Sustaining Treatment is currently enforced for terminally ill patients.

In the current study, the clinical nurses' attitudes toward WLST were moderate ( $3.68 \pm 0.45$ points out of 5 points). In the study by Lee and Kim [25], where nurses' attitudes were assessed using a different tool, the score was also moderate $(3.33 \pm 0.46$ points out of 5 points). These results indicate that clinical nurses' attitudes toward WLST should be changed positively.

The characteristics of clinical nurses that showed significant correlations with their attitudes toward WLST were age, education, religion, marital status, children, monthly household income, clinical experience, type of hospital, hospital department, experience of providing nursing care for patients with terminal illness or on their deathbed, experience with providing nursing care for patients who withdrew life-sustaining treatment, ethical values, experience of education on hospice care, and education on WLST. In other words, attitudes toward WLST were more positive among clinical nurses who were older, had a higher level of knowledge; were religious; had a spouse or child; had a higher monthly income; had more clinical experience; worked in a tertiary or general hospital (instead of a primary hospital) or in the hospice ward (instead of in other wards); had experience of providing nursing care for patients with terminal disease, end-of-life care, or those who withdrew life-sustaining medical care; had strong ethical values; or had experienced education on hospice care or WLST. Similar results were also reported in previous studies. Lee and Kim [25] stated that attitudes toward WLST were more positive among clinical nurses with more clinical experience than among those with less experience. In a study by Je and Hwa [16] on attitudes toward WLST among tertiary hospital workers and medical staff, the attitude was more positive among those working in hospice wards. Although the participants were different, it was also confirmed by Jung [4] that attitudes were affected by marital status, ethical values, and hospice education experience among nursing students. Kim and Mun [26] also reported that attitudes were related to having received education on WLST. Therefore, the factors found to be significantly related to attitudes in these studies include clinical experience, ward type, marital status, ethical values, and hospice care education experience. However, the effects of other general characteristics found in our study were not supported by previous studies. This may be attributed to the fact that prior studies mostly involved homogeneous groups of participants (i.e., nurses only working in the intensive care unit, nurses only working at tertiary hospitals, or nursing students), whereas we had fewer restrictions on the type of hospitals and wards and thus had participants from various institutions, such as primary hospitals, general hospitals, and tertiary hospitals. Therefore, there is a need for ongoing research on attitudes toward WLST among clinical nurses who work at various types of hospitals and in a diverse range of departments.

In this study, higher levels of knowledge of WLST in clinical nurses were associated with more positive attitudes toward WLST. In contrast, Kim et al. [11] reported that higher levels 
of knowledge of WLST were associated with more negative attitudes toward WLST among clinical nurses. The perceptions and value judgments of an individual affect the process of knowledge being transformed into attitudes [9]. Therefore, even if a nurse has sufficient knowledge of WLST, his or her attitudes toward WLST can be either positive or negative, depending on his or her ethical perspective on the dignity of human life, quality of life, and futile life-sustaining treatment. In addition, the positive correlation between knowledge of and attitudes toward WLST could have been affected by the timing of our study, which was conducted after a social consensus was reached on the need for an institutional safeguard, such as the Act on Decisions on Life-Sustaining Treatment. However, the level of knowledge of WLST and its relationship with attitudes toward WLST have been extremely rarely studied since the Life-Sustaining Medical Decision Act took effect. We believe that it is necessary to conduct ongoing, iterative research on the relationship between these two variables, as well as developing reliable assessment tools.

In the present study, higher levels of death anxiety among clinical nurses were associated with more negative attitudes toward WLST, which can be interpreted as indicating the same meaning as the finding reported by Choi and Jeong [27] that good death recognition was associated with more positive attitudes toward WLST among nursing students. Kang and Han [28] suggested that a higher level of understanding of the meaning of death and lower death anxiety in nurses would strengthen their will to respect the dignity of human life. Therefore, our result appears to indicate that nurses who had a low level of death anxiety realized human limitations and the limitedness of life, and were opposed to inflicting meaningless pain on patients, and their respect for life and the right to selfdetermination translated into positive attitudes toward WLST. However, Ko and Cho [14] reported a contradictory result that higher levels of anxiety were associated with more positive attitudes toward WLST among nurses. In our opinion, this was because they conducted their study before a social consensus on WLST was reached, and thus euthanasia and WLST were used interchangeably in the study. Therefore, in order to verify the relationship between the two variables, it is necessary to develop highly reliable assessment tools that enable a precise definition of attitudes toward WLST and to conduct extensive testing of this relationship in future studies.

In this study, higher perceptions of hospice care among clinical nurses were associated with more positive attitudes toward WLST. A direct comparison is not possible due to the lack of research on the relationship between perceptions of hospice care and attitudes toward WLST among nurses; however, our finding is consistent with previous observations, which were based on nurses, physicians, and administrative staff at a tertiary hospital [16] and nursing students [4]. We suggest that this correlation can be attributed to the fact that hospice care shares the same main concepts and purposes as WLST; namely, the goal is to provide medical care that does not cause pain to patients, to improve the quality of life for terminally ill patients, and to maintain human dignity.

In the present study, the attitudes of clinical nurses toward WLST were most strongly affected by their perceptions of hospice care, followed by having experienced providing nursing care for patients who withdrew life-sustaining medical care, death anxiety, marital status, and ethical values. Overall, these variables explained $43 \%$ of variance in attitudes toward WLST. In other words, high perceptions of hospice care, low death anxiety, experience of providing nursing care for patients who withdrew life-sustaining medical care, being married, and having firm ethical values had a positive influence on attitudes toward WLST. Although this finding cannot be compared with previous findings due to the lack of previous research involving nurses, it is consistent with the finding reported by Jung [4] that perceptions of hospice care were a major factor influencing attitudes toward WLST among nursing students. Hospice care refers to medical treatment aiming to provide terminally ill patients and their families with a dignified transition to death, as well as relief of pain and symptoms. Quality of death can also be construed as the quality of remaining life. In addition, WLST should not be equated to giving up on life; rather, it should be considered as an active expression of the patient's will to live without meaningless medical interventions in support of the right to self-determination. Therefore, perceptions of hospice care can be considered to be the most important factor in explaining attitudes toward WLST, and it should be improved to foster positive changes in attitudes toward WLST.

Another factor that affected attitudes toward WLST was having experienced providing nursing care for patients who 
withdrew life-sustaining treatment. Nurses in the intensive care unit who have gained experience caring for such patients may have a heightened perception of life-sustaining care [6]. Considering that hands-on experience transforms an individual's attitudes [29], the actual experience of providing nursing care for patients who withdraw life-sustaining treatment can be considered as an important factor in explaining attitudes toward WLST. Death anxiety was also shown to be a factor influencing attitudes toward WLST in the current study. There are no previous studies on the influence of death anxiety among nurses to which we can compare our finding, but in a similar vein, good death recognition was reported to have a positive influence on attitudes toward WLST [27]. In addition, the same result was observed among elderly cancer patients [13]. Thus, efforts to lower death anxiety can be considered as a way to instill positive attitudes toward WLST. Choosing to withdraw life-sustaining treatment involves reflecting on the meaning of death and accepting and choosing one's own death, and death and life-sustaining treatment cannot be considered separately. Therefore, we believe that additional studies should be conducted on death anxiety among nurses, as a factor affecting their attitudes toward WLST. We also found that having a spouse had a positive effect on attitudes toward WLST. As spouses are life companions who are supposed to support each other through thick and thin, married patients consider not only their own pain, but also the psychological and economic burden on the remaining spouse caused by the continuation of meaningless life-sustaining treatment [30], which appears to have resulted in their positive attitudes toward WLST. The last variable that explained attitudes toward WLST was ethical values. Nurses with firm ethical values were found to have positive attitudes toward WLST. In the same vein, Kim and Mun [26] reported that having firm ethical values had a positive influence on the attitudes of nursing students toward withholding of cardiopulmonary resuscitation, which is believed to indicate that people with firm ethical values make more rational decisions in the face of ethical conflicts.

We believe these results underscore the need for providing educational programs aimed at changing and improving perceptions of hospice care among clinical nurses in order to spur positive changes in their attitude toward WLST. Furthermore, these educational programs should include classes on how to lower death anxiety and strengthen ethical values, as well as simulation sessions or field training sessions through which nurses can practice caring for patients who withdraw lifesustaining treatment.

It is difficult to generalize our results beyond the respondents of this study because we included only nurses who worked at tertiary hospitals, general hospitals, or primary hospitals located in the same region. Our findings should be further investigated in future studies. Moreover, knowledge of and attitudes toward WLST after the Act on Decisions on LifeSustaining Treatment came into force should be investigated in large-scale survey research involving various hospitals located in various regions, and highly reliable assessment tools should be developed.

\section{CONFLICT OF INTEREST}

No potential conflict of interest relevant to this article was reported.

\section{ORCID}

Young Eun Lee, https://orcid.org/0000-0002-0854-0402

Yu Jin Jung, https://orcid.org/0000-0002-3079-7597

Yoo Na Jang, https://orcid.org/0000-0002-8124-4490

Hyo Eun Jeong, https://orcid.org/0000-0003-2805-9429

\section{AUTHOR'S CONTRIBUTIONS}

Conceptualization \& Methodology: YEL, YJJ. Data curation \& Formal analysis: YJJ, YNJ. Funding acquisition: YEL. Investigation: YJJ, YNJ, HEJ. Project administration \& Supervision: YEL, YJJ. Resources \& Software: YJJ. Validation: YEL, YJJ, YNJ, HEJ. Writing - original draft: YEL, YJJ. Writing review \& editing: YEL, YJJ, YNJ, HEJ.

\section{SUPPLEMENTARY MATERIALS}

Supplementary materials can be found via https://doi. org/10.14475/kjhpc.2020.23.3.114. 


\section{REFERENCES}

1. National Agency for Management of Life-Sustaining Treatment. Monthy statistics in 2018, 2019 [Internet]. Seoul: KONIBP; c2018-2019 [cited 2019 Dec 24]. Available from: https://www.lst.go.kr/comm/monthlyStatistics.do.

2. Ministry of Government legislation. Act on decisions on life-sustaining treatment for patients in hospice and palliative care or at the end of life in 2019 [Internet]. Sejong: Korea Ministry of Government Legislation; c1997-2019. [cited 2019 Dec 24]. Available from: http://www. law.go.kr/lsinfoP.do? lsiSeq=208166\&efYd=20190328\#0000.

3. Ministry of Health and Welfare. 1st Hospice and life-sustaining treatment comprehensive plan to ensure dignity and comfort from 2019 to 2023. Sejong: MOHW; c1997-2019. [cited 2019 Dec. 24]. Available from. http://www.mohw.go.kr/react/al/sal0301vw.jsp?PAR_MENU_ ID=04\&MENU_ID=0403\&CONT_SEQ=349863.

4. Jung YJ. The effect of nursing student's knowledge of life-sustaining treatment plan, consciousness of biomedical ethics, perception of hospice on the attitude toward withdrawal life-sustaining treatment [master's thesis]. Busan: Kosin Univ.; 2019. Korean.

5. Coombs MA, Parker R, Ranse K, Endacott R, Bloomer MJ. An integrative review of how families are prepared for, and supported during withdrawal of life sustaining treatment in intensive care. J Adv Nurs 2017;73:39-55.

6. LeeSJ, Kim HY. Experience of life-sustaining treatment in patient care among intensive care unit nurses: phenomenological approach. J Korean Acad Fundam Nurs 2016;23:172-83.

7. Kwon YO, Ahn SH. The attitude and perception on withdrawal of futile life sustaining treatment and patient self determination right among home care nurses. J Korean Bioethics Assoc 2013;14:53-66.

8. Kim SG, Kim SH, Yun HY. Factors that influence end-of-life care provided by nurses in general hospitals. Korean J Med Ethics 2019;22:53-72.

9. Ostrom TM. The relationship between the affective, behavioral and cognitive components of attitude. J Exp Soc Psychol 1969;5:12-30.

10. Kim EY, Seo EH, Jung EY. Knowledge and attitudes toward the withdrawal of life-sustaining treatment among nursing students. J East-West Nurs 2017;23:1-8.

11. Kim SJ, Kim HS, Chae Y, Kim WJ, Kang JS. The effect of nurses's experiences with DNR orders on their knowledge and attitudes concerning the withdrawal of life-sustaining treatment. Korean J Med Ethics 2012;15:355-69.

12. Templer DI. The construction and validation of a death anxiety scale. J Gen Psychol 1970;82:165-77.

13. Seo YM, Shin SJ. The relationship among attitudes toward the withdrawal of life-sustaining treatment, death anxiety, and death acceptance among hospitalized elderly cancer patients. Asian Oncol Nurs 2019;19:142-9.

14. Ko GH, Cho IS. Attitudes towards death and euthanasia among nurses and general population. Jour. of KoCon.a 2015;15:229-40.

15. Korea Hospice \& Palliative Nurse Association. Study guides for hospice and palliative care. Seoul:Sumunsa;2006.

16. Je NJ, Hwa JS. Factors influencing withdrawal of life-sustaining treatment in tertiary general hospital workers-knowledge and attitude of organ donation and transplantation, awareness of death, knowledge and perception of hospice palliative care. Korean J Hosp Palliat Care 2018;21:92-103.

17. Choi GH, Kwon SH. Effects of a hospice palliative education program on perception of hospice, attitude to death, and meaning of life in adults. Korean J Hosp Palliat Care 2018;21:14-22.

18. Kim SB. Knowledge to interruption of life-sustaining treatment and advance directives in nursing students [master's thesis]. Jeonju: Jeonbuk Univ.; 2011. Korean.

19. Collett L, Lester D. The fear of death and the fear of dying. J Psychol 1969;72:179-81.

20. Suh HK. The Relationships among life satisfaction, locus of control, and death anxiety as perceived by Korean and American older adults using selected personal demographic variables. Korean J Health Edu Promot 1987;4:95-135.

21. Han JY, Lee NY. Nursing students' attitude toward death and perception on hospice care. J Korean Oncol Nurs 2009;9:95-103.

22. Byun EK, Choi HR, Choi AL, Hong KH, Kim NM, Kim HS. An investigative research on the attitudes of intensive care unit nurses and families on terminating life support. J Korean Clin Nurs Res 2003;9:112-24.

23. Cho KH, Park YK, Suh SR. Comparison of the death anxiety and preferences for care near the end of life between nurses and physicians. Korean J Med Ethics 2017;20:276-86.

24. Lee YE, Choi EJ, Park JS, Shin SH. Perception and knowledge of hospice care and attitude toward death held by medical professionals from the same region in Korea. Korean J Hosp Palliat Care 2013;16:242-52.

25. Lee SJ, Kim HY. Attitude, role perception and nursing stress on life-sustaining treatment among intensive care unit nurses. Korean J Adult Nurs 2017;29:131-42.

26. Kim MY, Mun MY. Impact of biomedical ethics awareness and ethical values in nursing student on their attitudes towards DNR. Korean J Hosp Palliat Care 2018;21:115-23.

27. Choi EJ, Jeong HS. The effect of nursing students' consciousness of biomedical ethics, good death recognition, and self-esteem on the attitude toward withdrawal of life-sustaining treatment. JKAIS 2018;19:275-84.

28. Kang JH, Han SJ. A study of intensive care unit nurses' understanding of the meaning of death, death anxiety, death concern and respect for life. Korean J Hosp Palliat Care 2013;16:80-9. 
29. Kim HJ, Son MS, Kang IS. Nurses' knowledge, attitudes, experience, and confidence toward advance directives. Global Health and Nursing 2019;9:19-27.

30. Kim MH, Kang EH, Kim MY. Family decision-making to withdraw life-sustaining treatment for terminally-IIl patients in an unconscious state. Korean J Hosp Palliat Care 2012;15:147-54. 